\title{
HIV-1 Tat Regulates Occludin and A $\beta$ Transfer Receptor Expression in Brain Endothelial Cells via Rho/ROCK Signaling Pathway
}

\author{
Yanlan Chen, ${ }^{1}$ Wen Huang, ${ }^{1}$ Wenlin Jiang, ${ }^{1}$ Xianghong Wu, ${ }^{2}$ Biao Ye, ${ }^{1}$ and Xiaoting Zhou ${ }^{1}$ \\ ${ }^{1}$ Department of Neurology, First Affiliated Hospital, Guangxi Medical University, Nanning 530021, China \\ ${ }^{2}$ Department of Vasculocardiology, First Affiliated Hospital, Guangxi Medical University, Nanning 530021, China \\ Correspondence should be addressed to Wen Huang; hwen1229@163.com
}

Received 17 March 2016; Revised 16 June 2016; Accepted 4 July 2016

Academic Editor: Marta C. Monteiro

Copyright (C) 2016 Yanlan Chen et al. This is an open access article distributed under the Creative Commons Attribution License, which permits unrestricted use, distribution, and reproduction in any medium, provided the original work is properly cited.

HIV-1 transactivator protein (Tat) has been shown to play an important role in HIV-associated neurocognitive disorders. The aim of the present study was to evaluate the relationship between occludin and amyloid-beta $(\mathrm{A} \beta)$ transfer receptors in human cerebral microvascular endothelial cells (hCMEC/D3) in the context of HIV-1-related pathology. The protein expressions of occludin, receptor for advanced glycation end products (RAGE), and low-density lipoprotein receptor-related protein 1(LRP1) in hCMEC/D3 cells were examined using western blotting and immunofluorescent staining. The mRNA levels of occludin, RAGE, and LRP1 were measured using quantitative real-time polymerase chain reaction. HIV-1 Tat at $1 \mu \mathrm{g} / \mathrm{mL}$ and the Rho inhibitor hydroxyfasudil (HF) at $30 \mu \mathrm{mol} / \mathrm{L}$, with $24 \mathrm{~h}$ exposure, had no significant effect on hCMEC/D3 cell viability. Treatment with HIV-1 Tat protein decreased mRNA and protein levels of occludin and LRP1 and upregulated the expression of RAGE; however, these effects were attenuated by HF. These data suggest that the Rho/ROCK signaling pathway is involved in HIV-1 Tat-mediated changes in occludin, RAGE, and LRP1 in hCMEC/D3 cells. HF may have a beneficial influence by protecting the integrity of the blood-brain barrier and the expression of $\mathrm{A} \beta$ transfer receptors.

\section{Introduction}

Tight junction (TJ) proteins are essential components of blood-brain barrier (BBB) integrity [1,2]. Signaling between pericytes and endothelial cells is critical for $\mathrm{BBB}$ maintenance $[3,4]$. Occludin was the first integral membrane protein to be identified within TJs. Occludin has four transmembrane domains and a long $\mathrm{COOH}$-terminal cytoplasmic domain (domain E). Occludin itself can localize at TJs and directly associates with ZO-1 [5]. Occludin plays a pivotal role in maintaining the homeostasis of the central nervous system [2], and its destruction increases the diffusion of viruses and other microorganisms across the BBB [6].

BBB dysfunction appears to be a particularly important component of HIV-associated neurocognitive disorders (HAND) [7]. HIV-1 transactivator protein (Tat) can be actively released from HIV-1-infected cells and easily cross cell membranes and the BBB, causing HAND $[8,9]$. High levels of extracellular HIV-Tat have been recently reported in cerebrospinal fluid of HIV-infected patients [10]. HIV-1 Tat has been shown to disrupt TJs associated with astrocytes along the BBB, increasing the permeability of the barrier [11]. HIV-1 exposure also increases intracellular levels of amyloidbeta $(\mathrm{A} \beta)$ in human cerebral microvascular endothelial cells (hCMEC/D3) [12]. The BBB plays a critical role in both HIV-1 and $\mathrm{A} \beta$ pathology [13]. $\mathrm{BBB}$ disruption mediates some of the tissue damage that accompanies HIV-1 infection of the brain and so facilitates entry of the virus into the central nervous system [14]. The BBB endothelial cells respond to inflammatory stimuli, such as cytokines and $A \beta$, ultimately causing BBB disruption. Furthermore, the BBB plays a multifaceted role both upstream and downstream of the amyloid cascade to cause inflammation and oxidative stress, which can promote the accumulation of $A \beta$ in the brain [15]. Several HIV1 proteins have been shown to be amyloidogenic. HIV-1 Tat protein has been reported to inhibit $\mathrm{A} \beta$-degrading enzyme 
neprilysin, leading to increased levels of soluble $A \beta$ in cell culture [16].

Ras homolog gene family, member A (RhoA), is a small guanosine triphosphate-binding protein. Rho-associated kinase (ROCK) was the first downstream effector of Rho to be identified [17], and ROCK has been reported to mediate BBB disruption [18]. Rho-ROCK signaling was involved in mural cell recruitment to the vessel wall in brain, which was involved in maintaining BBB integrity [19]. Hydroxyfasudil (HF), a specific inhibitor of ROCK with strong effectiveness and selectivity $[20,21]$, promotes neuronal regeneration and is clinically used in patients with disorders such as spinal-cord injuries and stroke $[22,23]$. Therefore, ROCK can be considered a promising molecular target for the treatment of neurological diseases [24, 25].

However, whether the Rho/ROCK signaling pathway is involved in HIV-induced BBB disruption and the expression of $\mathrm{A} \beta$ transfer receptors is not completely understood. Therefore, the aim of the present study was to evaluate the relationship between occludin, $\mathrm{A} \beta$ transfer receptors, and the Rho/ROCK signaling pathway in hCMEC/D3 cells.

\section{Materials and Methods}

2.1. HIV-1 Tat. Recombinant HIV-1 Tat clade B protein (Prospec, Rehovot, Israel), produced in Escherichia coli, is formed of a single, nonglycosylated, polypeptide chain containing 86 amino acids encoded by exons, with a molecular mass of $14 \mathrm{kDa}$. The amino acid sequence is as follows: MEPVDPRLEP WKHPGSQPKT ACTNCYCKKC CFHCQVCFIT KALGISYGRK KRRQRRRPPQ GSQTHQVSLS KQPTSQSRGD PTGPKE. It is recommended that lyophilized HIV-1 Tat is stored desiccated below $-18^{\circ} \mathrm{C}$ and reconstituted in sterile $18 \mathrm{M} \Omega$ $\mathrm{cm} \mathrm{H}_{2} \mathrm{O}$.

2.2. Cell Cultures. hCMEC/D3 cells were provided as a gift from Dr. P.-O. Couraud (Institut Cochin, Paris, France). Endothelial basal medium (EBM)-2 (Lonza, Walkersville, MD, USA) was supplemented with $5 \%$ fetal bovine serum (Lonza, Switzerland), $1 \mathrm{ng} / \mathrm{mL}$ basic fibroblast growth factor (Sigma-Aldrich, USA), $5 \mu \mathrm{g} / \mathrm{mL}$ ascorbic acid (SigmaAldrich), 1/100 chemically defined lipid concentrate (Gibco, NY, USA), $10 \mathrm{mmol} / \mathrm{L}$ HEPES (Beyotime, Jiangsu, China), $1.4 \mu \mathrm{mol} / \mathrm{L}$ hydrocortisone (Sigma-Aldrich, USA), and $1 \%$ penicillin-streptomycin (Beyotime), as recommended by the manufacturer (Lonza, Walkersville, MD, USA). This solution is called complete EBM-2 medium. hCMEC/D3 cells were seeded into flasks coated with $1 \mathrm{mg} / \mathrm{mL}$ collagen type I (R\&D Systems) and cultured in complete EBM-2 medium, maintained at $37^{\circ} \mathrm{C}$ in a humidified atmosphere of $5 \% \mathrm{CO}_{2}$.

2.3. Cell Viability. hCMEC/D3 cells at the exponential growth phase were seeded onto 96-well plates at a density of $1 \times 10^{4}$ cells/well in $200 \mu \mathrm{L}$ serum-free medium and treated with HIV-1 Tat at various concentrations $(0,0.25,0.5,1$, or $1.250 \mu \mathrm{g} / \mathrm{mL}$ ), heat-inactivated Tat, or the Rho inhibitor HF $(0,10,30,50,80$, or $100 \mu \mathrm{mol} / \mathrm{L}$; Tianjin Chase Sun Pharmaceutical Co, Tianjin, China) for different periods of time $(0,6,12,24$, or $30 \mathrm{~h})$. The cells were incubated with $15 \mu \mathrm{L}$ 3-(4,5-dimethylthiazol-2-yl)-2, 5-diphenyltetrazolium bromide solution (MTT, $5 \mathrm{mg} / \mathrm{mL}$; Sigma-Aldrich, USA) for additional $4 \mathrm{~h}$ at $37^{\circ} \mathrm{C}$ and $5 \% \mathrm{CO}_{2}$. The optical density in each well was measured at $570 \mathrm{~nm}$ using a 96-well plate reader (Thermo Scientific, USA). HIV-1 Tat at $1 \mu \mathrm{g} / \mathrm{mL}$ and $\mathrm{HF}$ at $30 \mu \mathrm{mol} / \mathrm{L}$ for $24 \mathrm{~h}$ had no effect on the viability of hCMEC/D3 cells, so these concentrations were used in subsequent experiments.

hCMEC/D3 cells were pretreated with $30 \mu \mathrm{mol} / \mathrm{L}$ HF for $2 \mathrm{~h}$ prior to exposure to $1 \mu \mathrm{g} / \mathrm{mL} \mathrm{HIV-1} \mathrm{Tat,} \mathrm{and} \mathrm{cells}$ were then incubated for $24 \mathrm{~h}$ without serum. The HIV-1 Tat concentrations used in the present study are consistent with data from the literature, which indicate that concentrations of Tat in HIV-infected patients can reach the range of $\mu \mathrm{g} / \mathrm{mL}$ of serum [26]. Heat-inactivated Tat (as another control) was obtained by heating the protein at $90^{\circ} \mathrm{C}$ for $1 \mathrm{~h}$, which inactivates the biological potentials of Tat.

2.4. Western Blot Analysis. Treated endothelial cultures were washed three times and lysed in a RIPA cell lysis buffer (Beyotime) containing protease inhibitor cocktail tablets (Beyotime). The lysates were centrifuged at $12,000 \times \mathrm{g}$ for $15 \mathrm{~min}$, the supernatants were collected, and protein concentrations were measured using the BCA Protein Assay Kit (Beyotime). Total proteins were mixed with 5x SEMSPAGE protein sample buffer solution (Beyotime), then boiled for $5 \mathrm{~min}$ at $100^{\circ} \mathrm{C}$, and stored at $-20^{\circ} \mathrm{C}$ until use. Equal masses of proteins $(20 \mu \mathrm{g})$ were separated on SDSpolyacrylamide gel and electrophoresed. Proteins were blotted onto polyvinylidene fluoride membranes $(0.22 / 0.45 \mu \mathrm{m}$; Millipore, Billerica, MA, USA). The membranes were blocked with $5 \%$ fat-free milk at room temperature for $1 \mathrm{~h}$ and then incubated at $4^{\circ} \mathrm{C}$ overnight with different primary antibodies diluted in primary antibody dilution buffer (Beyotime). The primary antibodies were as follows: occludin $(1: 1000$, mouse monoclonal antibody; Invitrogen, Carlsbad, CA, USA), RAGE ( $1: 1000$, rabbit monoclonal antibody; Abcam), LRP1 (1:10,000, rabbit monoclonal antibody; Abcam), and GAPDH (1:10,000; Proteintech Group, Chicago, IL, USA). The membranes were then incubated for $1 \mathrm{~h}$ with IRDye 680RD goat anti-rabbit immunoglobulin (Ig) G and IRDye 680RD goat anti-mouse IgG secondary antibodies (both 1:10,000; LI-COR Biosciences, Lincoln, NE, USA) diluted in secondary antibody dilution buffer (Beyotime). Proteins were visualized by scanning the membrane on an Odyssey Infrared Imaging System (LI-COR Biosciences) with the 700 and $800 \mathrm{~nm}$ channels. The density of bands was calculated using Image-J software (National Institutes of Health, Bethesda, MD, USA). Protein levels were represented by the ratios of optical densities in their bands, normalized against GAPDH.

2.5. Reverse Transcription- (RT-) PCR and Quantitative RealTime PCR. Total RNA was extracted from hCMEC/D3 cells using TRIzol reagent (Invitrogen) and reverse transcribed into cDNA using the Prime-Script RT reagent kit (Takara Bio, Dalian, Japan) according to the manufacturer's instructions. The resulting cDNA was used as a template for RT-PCR. 
The primer sequences were as follows: occludin (Invitrogen): $5^{\prime}$-TCAGGGAATATCCACCTATCACTTCAG- $3^{\prime}$ and $5^{\prime}$-CATCAGCAGCAGCCATGTACTCTTCAC- ${ }^{\prime}$; RAGE (Takara): $5^{\prime}$-CAACGGCTCCCTCTTCCTT- $3^{\prime}$ and $5^{\prime}$-TTGGTCTCCTTTCCATTCCTGT-3' ${ }^{\prime}$; LRP1 (Takara): $5^{\prime}$-CGCCTCCTACCACTTCCAAC- $3^{\prime}$ and $5^{\prime}$-CGCCACCTCAATCACATCTC-3' ${ }^{\prime}$; and GAPDH (Invitrogen): $5^{\prime}$-GCACCGTCAAGGCTGAGAAC- $3^{\prime}$ and $5^{\prime}$-TGGTGAAGACGCCAGTGGA-3'. Quantitative RT-PCR was performed using a Taq PCR Master Mix Kit (Takara) and conducted on the ABI Prism 7500 sequence detection system (Applied Biosystems, USA) using RT Reaction Mix in a total volume of $20 \mu \mathrm{L}$ at $25^{\circ} \mathrm{C}$ for $10 \mathrm{~min}, 42^{\circ} \mathrm{C}$ for $30 \mathrm{~min}$, and $94^{\circ} \mathrm{C}$ for $5 \mathrm{~min}$. GAPDH served as an internal control in relative RT-PCR. The relative levels of the target genes were quantified using $2^{-\Delta \Delta \mathrm{Ct}}$ method.

2.6. Immunofluorescence Microscopy. hCMEC/D3 cells were seeded onto circular glass coverslips in a 24 -well plate and incubated for $24 \mathrm{~h}$. The cells were fixed for $30 \mathrm{~min}$ with $4 \%$ paraformaldehyde (Solarbio, Beijing, China) on ice and permeabilized with $0.1 \%$ Triton X-100 (Beyotime) for $5 \mathrm{~min}$. Samples were incubated in blocking solution of $3 \%$ bovine serum albumin (Sigma, USA) for $1 \mathrm{~h}$ at room temperature and in antibodies against LRP1 $(1: 200$, rabbit monoclonal antibody; Abcam) and RAGE (1:200, rabbit polyclonal antibody; Abcam) at $4^{\circ} \mathrm{C}$ overnight. The secondary antibodies, Alexa Fluor-488 donkey anti-rabbit (1:200; Invitrogen) and Alexa Fluor 594 donkey anti-mouse (1:200; Invitrogen), were added and incubated for $2 \mathrm{~h}$, then stained with $4^{\prime}, 6$ diamidino-2-phenylindole (Invitrogen), and visualized using a fluorescence microscope (Nikon Al; Nikon).

2.7. Statistical Analysis. The results are expressed as means \pm standard deviation. SPSS version 17.0 (SPSS, Chicago, IL, USA) was used to perform statistical analyses. Comparisons between groups were conducted using a parametric test (one-way analysis of variance) combined with a multiple comparison test (least-squares difference or the Bonferroni post hoc test). Statistical significance was set at $p<0.05$.

\section{Results}

3.1. Cell Viability. hCMEC/D3 viability was tested using an MTT assay. HIV-1 Tat at $1 \mu \mathrm{g} / \mathrm{mL}$ and $\mathrm{HF}$ at $30 \mu \mathrm{mol} / \mathrm{L}$ with $24 \mathrm{~h}$ exposure had no significant effect on hCMEC/D3 cell viability (Figure 1).

3.2. The RhoA/ROCK Signaling Pathway Is Involved in HIV-1 Tat-Induced Changes in Occludin Expression. To observe the effects of HIV-1 Tat on expression levels of the TJ protein occludin, hCMEC/D3 cells were exposed to $1 \mu \mathrm{g} / \mathrm{mL}$ HIV-1 Tat for $24 \mathrm{~h}$. The protein levels of occludin were significantly lower in the HIV-1 Tat group than in the control group (Figure 2(a)). With exposure to HIV-1 Tat for $12 \mathrm{~h}$, the mRNA expression of occludin, as examined by real-time RT-PCR, was consistent with the protein levels (Figure 2(b)).

To explore whether RhoA/ROCK signaling is involved in HIV-1 Tat-induced downregulation of occludin, hCMEC/D3 cells were pretreated for $2 \mathrm{~h}$ with $30 \mu \mathrm{mol} / \mathrm{L} \mathrm{HF}$, followed by coexposure to HF and $1 \mu \mathrm{g} / \mathrm{mL}$ HIV-1 Tat for $24 \mathrm{~h}$ (for western blotting) or $12 \mathrm{~h}$ (for real-time RT-PCR). Occludin protein and mRNA levels were significantly increased with coexposure to HF and HIV-1 Tat compared with HIV-1 Tat only (Figures 2(a) and 2(b)).

3.3. HIV-1 Tat-Induced Changes in LRP1 and RAGE Expression. To observe whether HIV-1 Tat could affect the expression of $\mathrm{A} \beta$ transporters in $\mathrm{hCMEC} / \mathrm{D} 3$ cells, the expression of LRP1 and RAGE was examined using western blotting, real-time RT-PCR, and immunoreactivity. Western blotting showed that the expression of RAGE was significantly increased compared to the control group following treatment with $1 \mu \mathrm{g} / \mathrm{mL}$ HIV-1 Tat, while LRP1 expression was downregulated (Figures 3(a) and 4(a)). Treatment with HIV-1 Tat also significantly decreased LRP1 mRNA and increased RAGE mRNA levels, consistent with the protein levels (Figures 3(b) and 4(b)), and resulted in markedly stronger RAGE and weaker LRP1 immunoreactivity compared with the untreated group (Figures 3(c) and 4(c)).

3.4. The RhoA/ROCK Signaling Pathway Is Involved in the HIV-1 Tat-Induced Regulation of LRP1 and RAGE Expression. To investigate whether HF can protect against HIV-1 Tatinduced changes in LRP1 and RAGE expression, hCMEC/D3 cells were cotreated with HF and HIV-1 Tat for $24 \mathrm{~h}$ (for western blotting and immunofluorescence staining) or for $12 \mathrm{~h}$ (for real-time RT-PCR). As shown in Figures 3 and 4, HF downregulated RAGE expression and increased LRP1 protein levels. These results were consistent with those for RAGE and LRP1 mRNA levels, which significantly differed in the groups cotreated with HF and HIV-1 Tat versus HIV-1 Tat only.

\section{Discussion}

Although the mechanisms by which HIV invades the brain process are not fully understood, alterations of TJ protein expression can contribute, at least in part, to this phenomenon [27]. HIV-1 Tat is known to trigger oxidative stressdependent apoptosis of neurons both in vitro and in vivo $[9,28]$. Exposure to HIV-1 Tat has also been shown to disrupt the integrity of the BBB and result in endothelial hyperpermeability and increased transendothelial migration, as reported in our previous in vitro [1] and in vivo studies [28]. Tat clade $B$ is more neuropathogenic, disrupts the integrity of the BBB to a greater extent than Tat clade C [29], and was therefore used in the current study. Our results demonstrate that HIV-1 Tat at $1 \mu \mathrm{g} / \mathrm{mL}$ and the Rho inhibitor HF at $30 \mu \mathrm{mol} / \mathrm{L}$, with $24 \mathrm{~h}$ exposure, had no significant effect on hCMEC/D3 cell viability (Figure 1).

Previous reports have indicated that ROCK plays a role in ischemic stroke and edema formation [30]. Rho signaling is involved in the regulation of TJs; Rho directly phosphorylates occludin and other TJ proteins [31]; and Rhokinase inhibitor improves cerebral integrity and function by regulating endothelial cell oxidative stress and reorganizing intercellular junctions after acute ischemic attacks [30]. In 


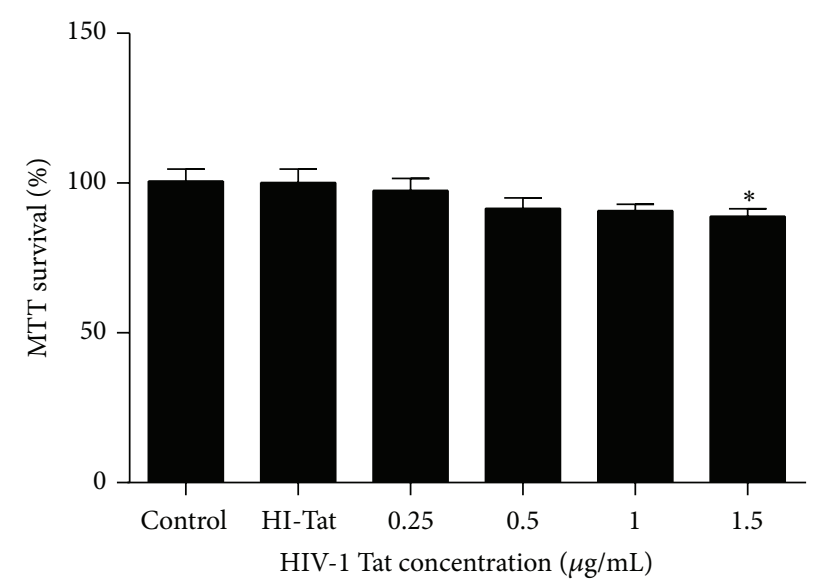

(a)

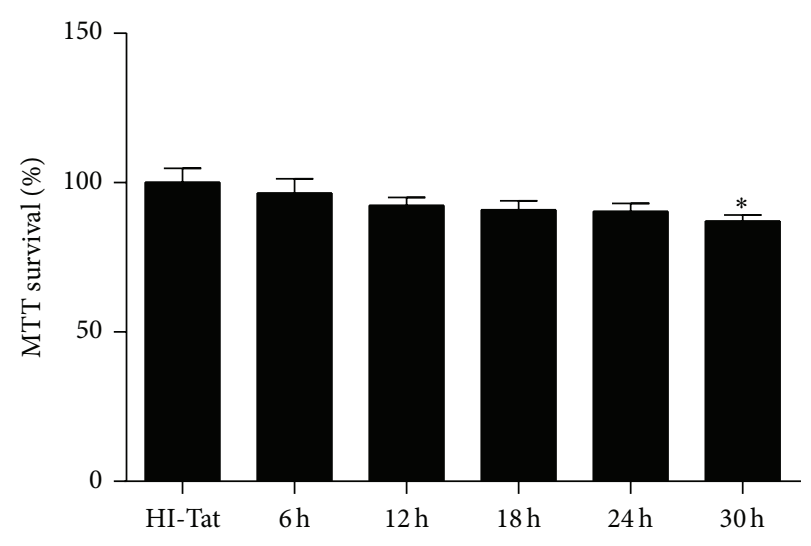

(b)

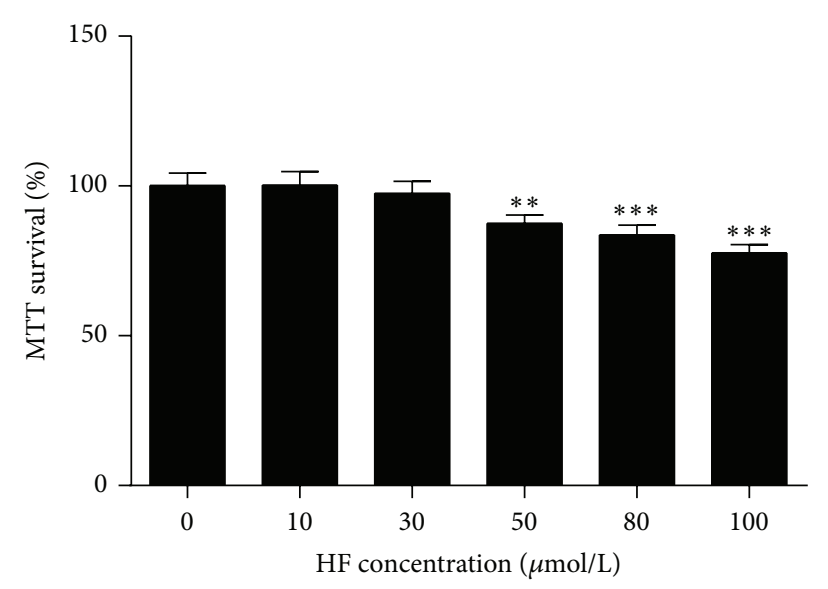

(c)

FIGURE 1: Cell viability. hCMEC/D3 cells were treated with HIV-1 Tat ((a), (b)) at different concentrations $(0,0.25,0.5,1$, or $1.25 \mu \mathrm{g} / \mathrm{mL})$ or heat-inactivated Tat or $\operatorname{HF}(0,10,30,50,80$, or $100 \mu \mathrm{mol} / \mathrm{L})$ (c) for different durations $(0,6,12,24$, and $30 \mathrm{~h})$, with cell viability detected using an MTT assay. Cell viability was not affected by $1 \mu \mathrm{g} / \mathrm{mL}$ HIV-1 Tat or $30 \mu \mathrm{mol} / \mathrm{L}$ HF for $24 \mathrm{~h}$. Results are shown as means \pm standard error of the mean $(n=5) .{ }^{*} p<0.05,{ }^{* *} p<0.01$, and ${ }^{* * *} p<0.001$ versus control.

addition, inhibition of Rho activity has been reported to protect against Tat-induced alterations in total and nuclear ZO-1 protein levels [32], while ROCK inhibitor has been reported to preserve occludin and $\mathrm{ZO}-1$ levels in the brain or primary human brain microvascular endothelial cells $[33,34]$. In the present study, HF upregulated the protein and mRNA levels of occludin, the destruction of which was induced by HIV1 Tat (Figures 2(a) and 2(b)). HF protected against HIV1 Tat-mediated $\mathrm{BBB}$ dysfunction partly by inhibiting the RhoA/ROCK signaling pathway.

HIV-Tat is a ligand for LRP1 and it may compete with $\mathrm{A} \beta$ leading to decreased clearance of $\mathrm{A} \beta$ from the brain and promoting its deposition [35]. HIV-1 Tat has also been reported to significantly increase $A \beta$ levels in postmortem brain samples from patients infected with HIV-1 [16]. HIV-1 exposure increases the intracellular levels of $\mathrm{A} \beta$ in hCMEC/D3 cells [12]. HIV-1 Tat inhibits the uptake of $\mathrm{A} \beta$ by primary mouse microglial cells [36]. Furthermore, the induction of HIV-1 Tat in astrocytes has been shown to increase neuronal damage, tau phosphorylation, and $\mathrm{A} \beta$ plaque formation in $\mathrm{APP} /$ presenilin-1 transgenic mice [37], suggesting an important role for HIV-1 Tat in the development of HAND. However, the molecular mechanisms involved in HIV-1 Tatevoked $\mathrm{A} \beta$ deposition in the brain remain largely unknown. Neurodegeneration and dementia in Alzheimer's disease may involve similar molecular mechanisms as those involved in HIV-associated dementia [12, 38].

However, the $\mathrm{A} \beta$ deposition pattern in HIV appears to be distinct from that of Alzheimer's disease, in which extracellular senile plaques are a predominant feature. In the $\mathrm{HIV}$-infected brain, $\mathrm{A} \beta$ accumulates primarily as diffuse and intraneuronal deposits [39]. Peptides and proteins generally do not cross the BBB [40], but they can be transported into the brain via specific transport systems [41]. RAGE and LRP1 remain the most interesting targets. Transport of $A \beta$ from the bloodstream into the brain is mediated by RAGE, while $A \beta$ transport from the brain into the bloodstream is mediated by LRP1 $[42,43]$. RAGE is a multiligand receptor in IgG 


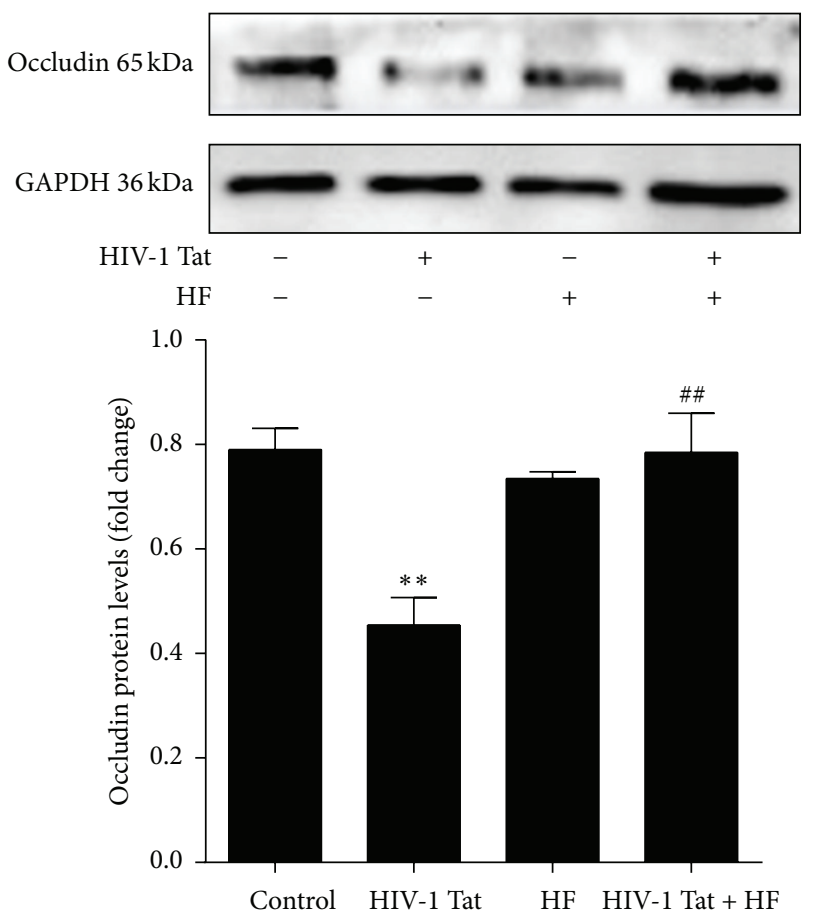

(a)

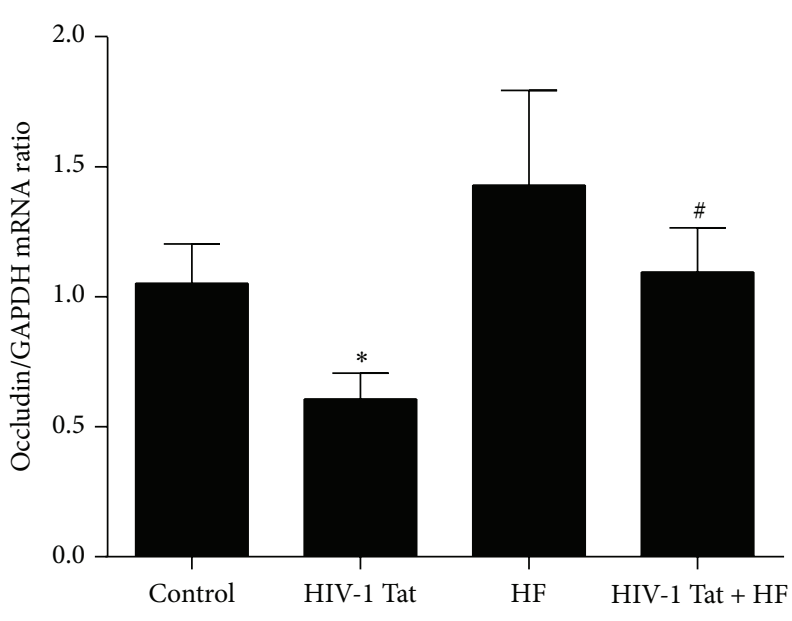

(b)

FIgURE 2: Role of RhoA/ROCK signaling in HIV-1 Tat-induced changes in occludin. hCMEC/D3 cells were pretreated with HF (30 $\mu$ mol/L) $2 \mathrm{~h}$ prior to the addition of occludin. HIV-1 Tat treatment was continued for $24 \mathrm{~h}$ for western blotting (a) and for $12 \mathrm{~h}$ for RT-PCR (b). HIV-1 Tat exposure was associated with decreased protein and mRNA levels of occludin in hCMEC/D3 cells. With coexposure to HF and HIV-1 Tat, occludin protein and mRNA levels were significantly increased when compared with exposure to HIV-1 Tat only. Data are expressed as means \pm standard error of the mean $(n=3$, values determined by the ratio to GAPDH, for $(\mathrm{a}), n=5$ for $(\mathrm{b})) .{ }^{*} p<0.05$ and ${ }^{* *} p<0.01$ versus control; ${ }^{\#} p<0.05$ and ${ }^{\# \#} p<0.01$ versus HIV-1 Tat.

superfamily that binds soluble $\mathrm{A} \beta$ and mediates pathophysiologically relevant cellular responses consequent to ligation by a variety of ligands [42]. LRP1 is a multiligand lipoprotein receptor that interacts with a broad range of secreted proteins and resident cell-surface molecules, mediating their endocytosis or activating signaling pathways through multiple cytosolic adaptor and scaffold proteins [44]. Increased RAGE and decreased LRP1 immunoreactivity within the microvasculature have been found in Alzheimer's disease patients [43]. Blocking RAGE with a specific neutralizing antibody can protect against the accumulation of exogenous $\mathrm{A} \beta$ in HIV1-exposed hCMEC/D3 cells [12]. In the current study, $24 \mathrm{~h}$ exposure to HIV-1 Tat resulted in markedly stronger RAGE immunoreactivity and increased RAGE mRNA levels compared with the control group (Figure 3). This may directly lead to increased $A \beta$ deposition in the brain. In contrast to the alterations in RAGE expression, exposure to HIV-1 Tat attenuated LRP1 levels in hCMEC/D3 cells (Figure 4). Our data suggest that HF may prevent the movement of $A \beta$ into the brain and stimulate brain $A \beta$ clearance across the $\mathrm{BBB}$ (Figure 5). The RhoA/ROCK signaling pathway plays a favorable role in maintaining $A \beta$ homeostasis at the level of the BBB. However, different effects of HIV-1 on LRP1 have been observed. For example, HIV-1 p24 had no effects on LRP1 levels in an in vitro study [12]. The reason for this might be that different HIV subtype proteins affect LRP1 via multiple signaling pathways.

\section{Conclusions}

In the current study, the Rho-kinase inhibitor HF significantly inhibited HIV-1 Tat-induced occludin dysfunction and regulated LRP1 and RAGE expression in hCMEC/D3 cells, suggesting a potential protective role for HF in HIV1 Tat-mediated $\mathrm{BBB}$ destruction and $\mathrm{A} \beta$ accumulation. $\mathrm{A}$ better understanding of the mechanisms involved in $A \beta$ deposition in the brain during HIV-1 infection will help with the development of new therapeutic strategies for reducing the $\mathrm{A} \beta$ burden in HAND.

\section{Competing Interests}

The authors declare no competing interests regarding the publication of this paper.

\section{Acknowledgments}

This work was supported by the National Nature Science Foundation of China (81160152 and 81371333) and the Guangxi Nature Science Foundation (2013GXNSFCA019013). 


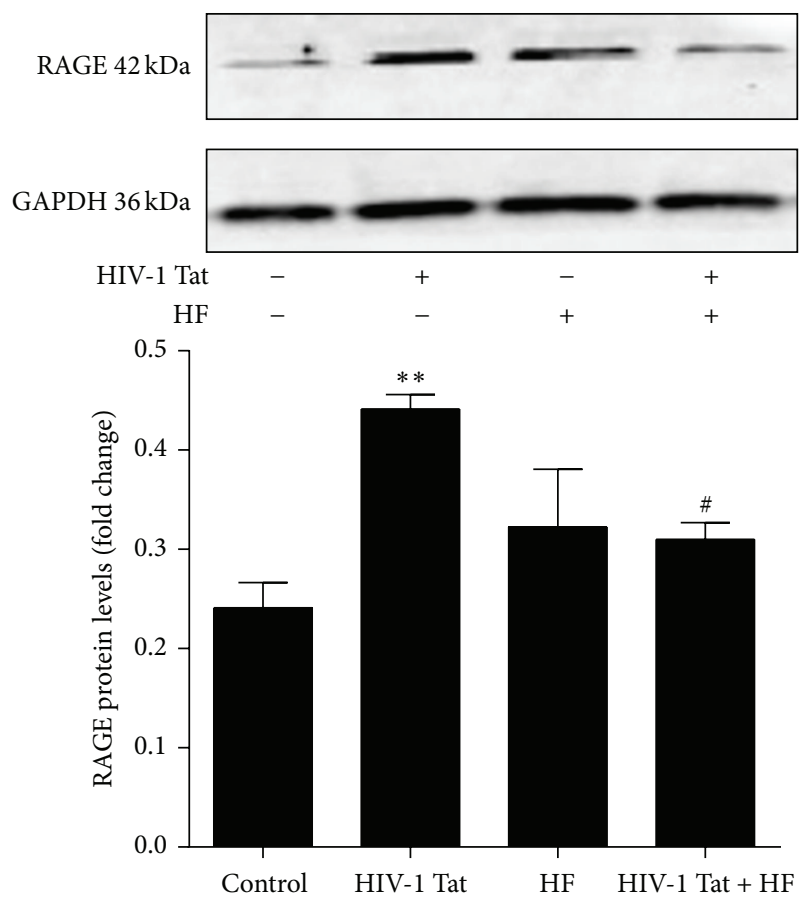

(a)
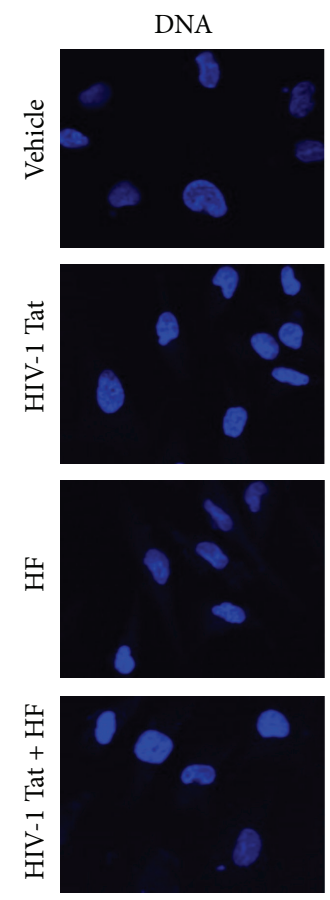

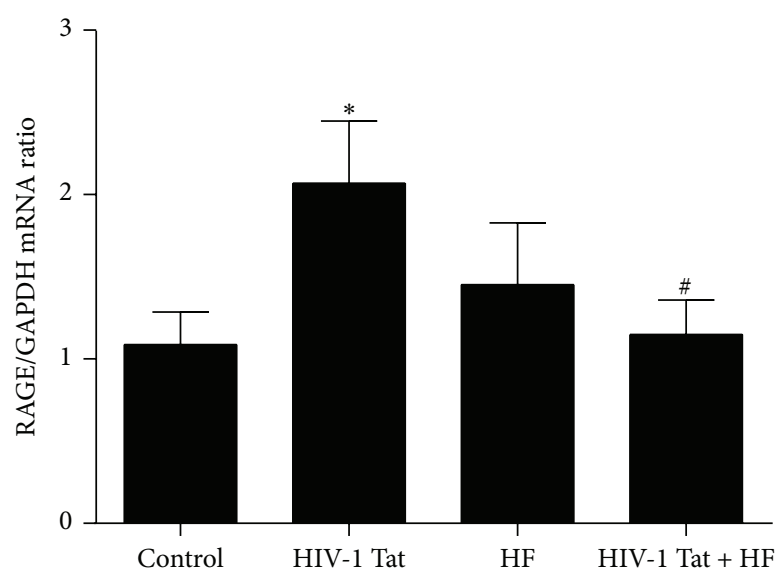

(b)
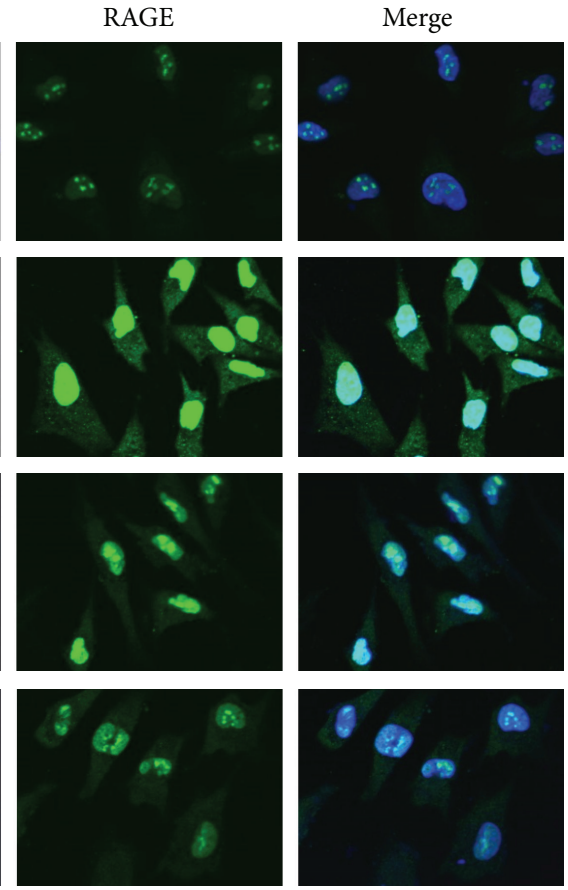

(c)

FIGURE 3: Role of RhoA/ROCK signaling in HIV-1 Tat-induced changes in RAGE. Exposure to HIV-1 Tat resulted in markedly higher levels of RAGE protein (a) and mRNA (b) and stronger immunoreactivity (c) compared with the untreated group. hCMEC/D3 cells were pretreated with HF $(30 \mu \mathrm{mol} / \mathrm{L}) 2 \mathrm{~h}$ prior to HIV-1 Tat treatment for $24 \mathrm{~h}$. RAGE protein and mRNA levels and immunoreactivity were significantly decreased with coexposure to HF and HIV-1 Tat compared with HIV-1 Tat only. Data are expressed as means \pm standard error of the mean ( $n=3$, values determined by the ratio to GAPDH, for (a), $n=5$ for (b)). ${ }^{*} p<0.05$ and ${ }^{* *} p<0.01$ versus control; ${ }^{*} p<0.05$ versus HIV-1 Tat. 


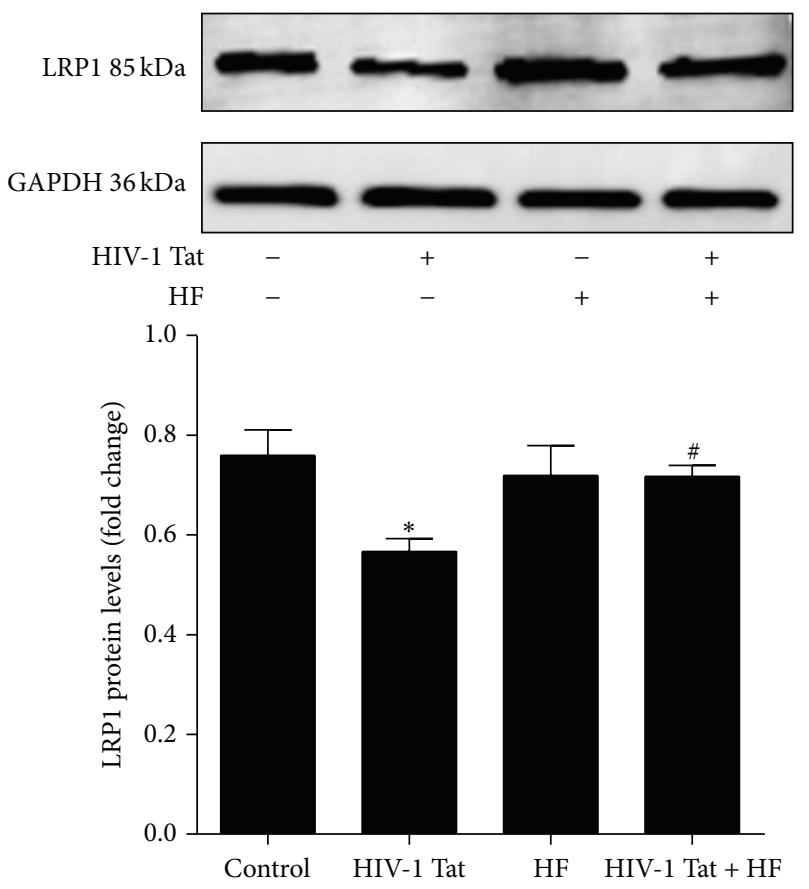

(a)
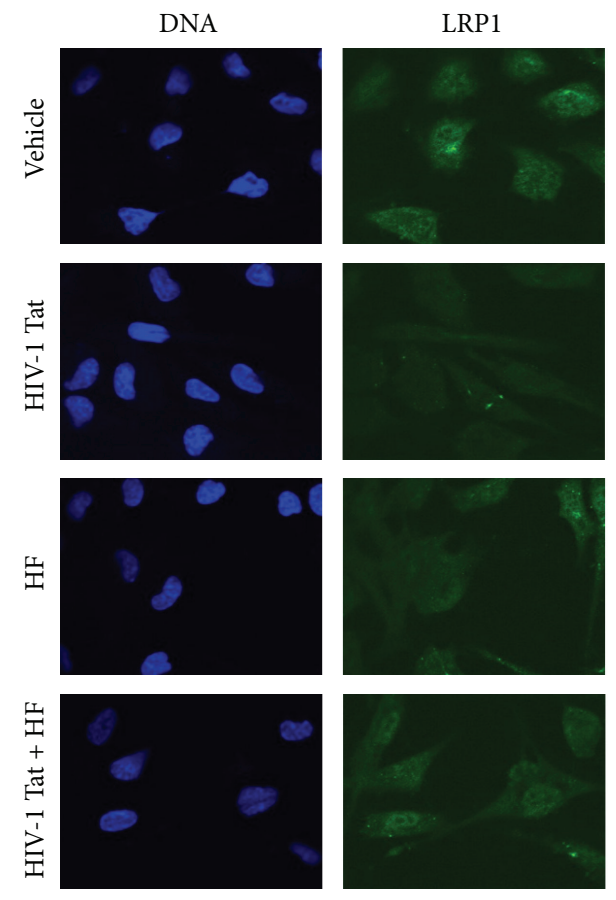

(c)

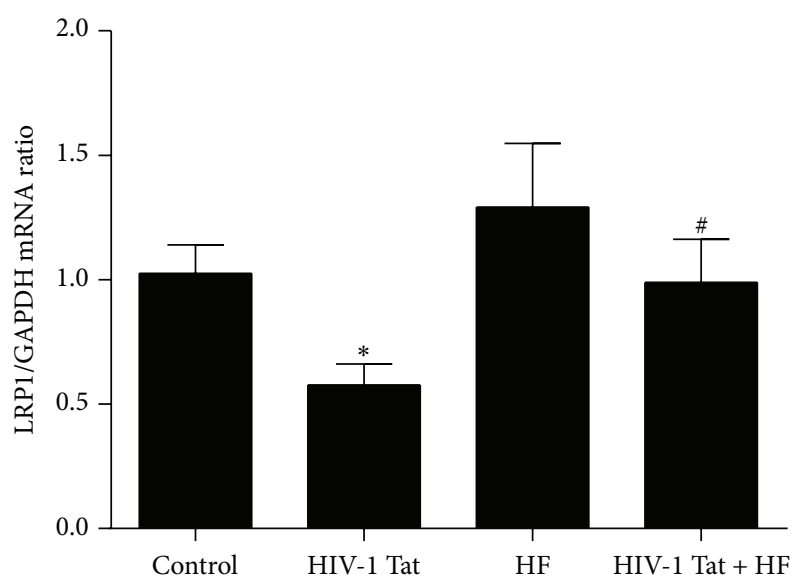

(b)
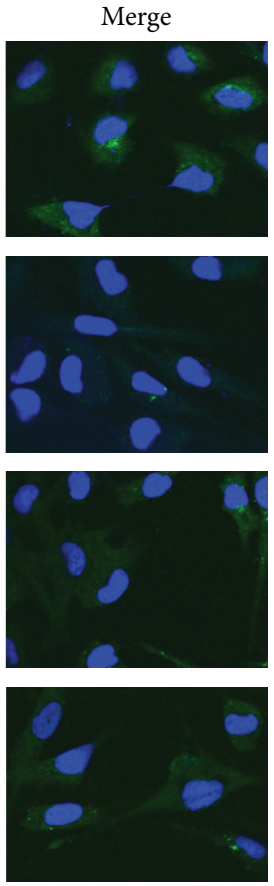

Figure 4: Role of RhoA/ROCK signaling in HIV-1 Tat-induced changes in LRP1. Exposure to HIV-1 Tat resulted in markedly lower levels of LRP1 protein (a) and mRNA (b) and weaker immunoreactivity (c) compared with the untreated group. hCMEC/D3 cells were pretreated with $\mathrm{HF}(30 \mu \mathrm{mol} / \mathrm{L}) 2 \mathrm{~h}$ prior to HIV-1 Tat treatment for $24 \mathrm{~h}$. LRP1 protein and mRNA levels and immunoreactivity were significantly increased with coexposure to HF and HIV-1 Tat compared with HIV-1 Tat only. Data are expressed as means \pm standard error of the mean $(n=3$, values determined by the ratio to GAPDH, for (a), $n=5$ for (b)). ${ }^{*} p<0.05$ versus control; ${ }^{\#} p<0.05$ versus HIV-1 Tat. 


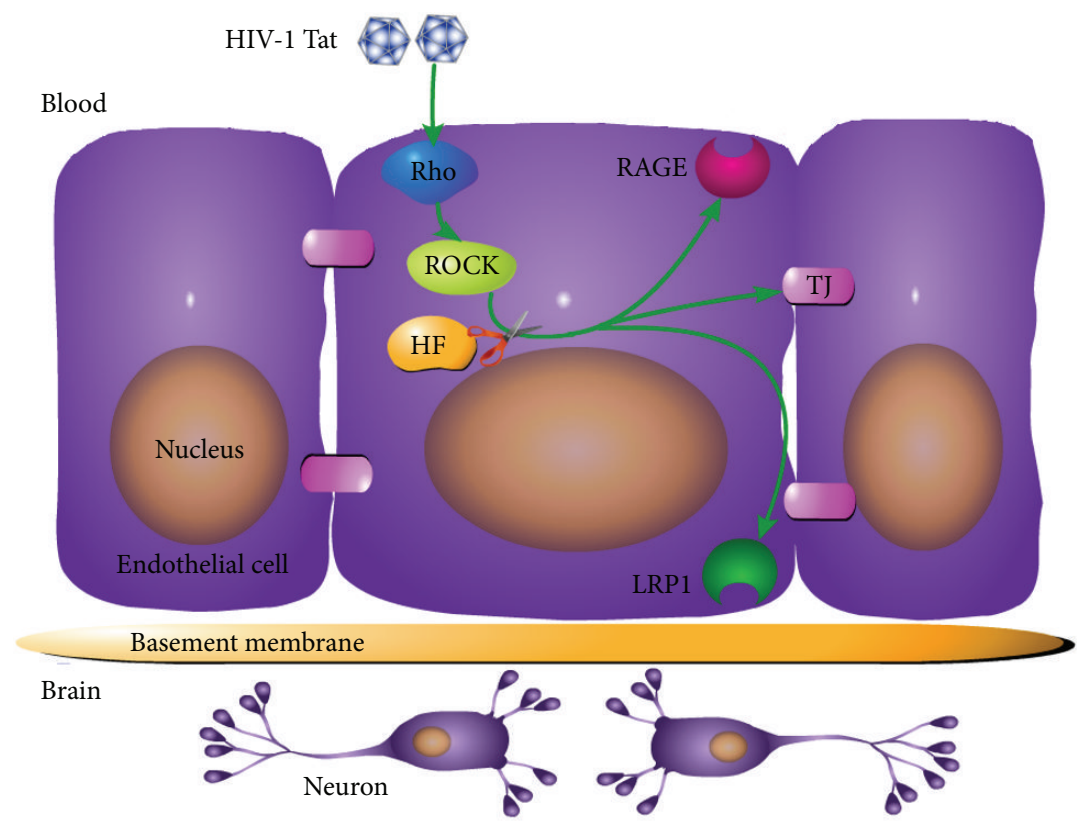

FIGURE 5: Schematic diagram illustrating the effects of HIV-1 Tat on occludin, RAGE, and LRP1 in brain endothelial cells. Exposure to HIV-1 Tat resulted in RAGE overexpression, which downregulated occludin and LRP1, stimulating the transfer of A $\beta$ from the blood into the brain. HF protected against these effects. Exposure to HF inhibited HIV-1 Tat-induced dysregulation of occludin, RAGE, and LRP1.

\section{References}

[1] W. Huang, Y. E. Sung, I. E. András, B. Hennig, and M. Toborek, "PPAR $\alpha$ and PPAR $\gamma$ attenuate HIV-induced dysregulation of tight junction proteins by modulations of matrix metalloproteinase and proteasome activities," The FASEB Journal, vol. 23, no. 5, pp. 1596-1606, 2009.

[2] M. Saitou, M. Furuse, H. Sasaki et al., "Complex phenotype of mice lacking occludin, a component of tight junction strands," Molecular Biology of the Cell, vol. 11, no. 12, pp. 4131-4142, 2000.

[3] R. D. Bell, E. A. Winkler, A. P. Sagare et al., "Pericytes control key neurovascular functions and neuronal phenotype in the adult brain and during brain aging," Neuron, vol. 68, no. 3, pp. 409427, 2010 .

[4] Z. Zhao, A. R. Nelson, C. Betsholtz, and B. V. Zlokovic, "Establishment and dysfunction of the blood-brain barrier," Cell, vol. 163, no. 5, pp. 1064-1078, 2015.

[5] M. Furuse, M. Itoh, T. Hirase et al., "Direct association of occludin with ZO-1 and its possible involvement in the localization of occludin at tight junctions," Journal of Cell Biology, vol. 127, no. 6, pp. 1617-1626, 1994.

[6] L.-H. Qin, W. Huang, X.-A. Mo, Y.-L. Chen, and X.-H. Wu, "LPS induces occludin dysregulation in cerebral microvascular endothelial cells via MAPK signaling and augmenting MMP2 levels," Oxidative Medicine and Cellular Longevity, vol. 2015, Article ID 120641, 9 pages, 2015.

[7] I. E. András, G. Rha, W. Huang et al., "Simvastatin protects against amyloid $\beta$ and HIV-1 Tat-induced promoter activities of inflammatory genes in brain endothelial cells," Molecular Pharmacology, vol. 73, no. 5, pp. 1424-1433, 2008.

[8] W. Kang, W. A. Marasco, H. Tong et al., "Anti-tat Hutat2:Fc mediated protection against tat-induced neurotoxicity and HIV-1 replication in human monocyte-derived macrophages," Journal of Neuroinflammation, vol. 11, no. 1, article 195, 2014.
[9] B. P. Irish, Z. K. Khan, P. Jain et al., "Molecular mechanisms of neurodegenerative diseases induced by human retroviruses: a review," American Journal of Infectious Diseases, vol. 5, no. 3, pp. 238-258, 2009.

[10] T. P. Johnson, K. Patel, K. R. Johnson et al., "Induction of IL-17 and nonclassical T-cell activation by HIV-Tat protein," Proceedings of the National Academy of Sciences of the United States of America, vol. 110, no. 33, pp. 13588-13593, 2013.

[11] I. E. Cisneros and A. Ghorpade, "HIV-1, Methamphetamine and astrocyte glutamate regulation: combined excitotoxic implications for neuro-AIDS," Current HIV Research, vol. 10, no. 5, pp. 392-406, 2012.

[12] I. E. András, S. Y. Eum, W. Huang, Y. Zhong, B. Hennig, and M. Toborek, "HIV-1-induced amyloid beta accumulation in brain endothelial cells is attenuated by simvastatin," Molecular and Cellular Neuroscience, vol. 43, no. 2, pp. 232-243, 2010.

[13] I. E. András and M. Toborek, "HIV-1 stimulates nuclear entry of amyloid beta via dynamin dependent EEA1 and TGF- $\beta /$ Smad signaling," Experimental Cell Research, vol. 323, no. 1, pp. 66-76, 2014.

[14] P. Annunziata, "Blood-brain barrier changes during invasion of the central nervous system by HIV-1: old and new insights into the mechanism," Journal of Neurology, vol. 250, no. 8, pp. 901906, 2003.

[15] M. A. Erickson and W. A. Banks, "Blood-brain barrier dysfunction as a cause and consequence of Alzheimer's disease," Journal of Cerebral Blood Flow and Metabolism, vol. 33, no. 10, pp. 15001513, 2013.

[16] H. C. Rempel and L. Pulliam, "HIV-1 Tat inhibits neprilysin and elevates amyloid $\beta$,” AIDS, vol. 19, no. 2, pp. 127-135, 2005.

[17] M. Amano, Y. Fukata, and K. Kaibuchi, "Regulation and functions of Rho-associated kinase," Experimental Cell Research, vol. 261, no. 1, pp. 44-51, 2000. 
[18] K. Liu, Z. Li, T. Wu, and S. Ding, "Role of Rho kinase in microvascular damage following cerebral ischemia reperfusion in rats," International Journal of Molecular Sciences, vol. 12, no. 2, pp. 1222-1231, 2011.

[19] E. Montanez, S. A. Wickström, J. Altstätter, H. Chu, and R. Fässler, " $\alpha$-parvin controls vascular mural cell recruitment to vessel wall by regulating RhoA/ROCK signalling," The EMBO Journal, vol. 28, no. 20, pp. 3132-3144, 2009.

[20] J. Liu, H.-Y. Gao, and X.-F. Wang, "The role of the Rho/ROCK signaling pathway in inhibiting axonal regeneration in the central nervous system," Neural Regeneration Research, vol. 10, no. 11, pp. 1892-1896, 2015.

[21] D. Kentrup, S. Reuter, U. Schnöckel et al., "Hydroxyfasudilmediated inhibition of ROCK1 and ROCK2 improves kidney function in rat renal acute ischemia-reperfusion injury," PLOS ONE, vol. 6, no. 10, Article ID e26419, 2011.

[22] M. Li, D. Yasumura, A. A. K. Ma et al., "Intravitreal administration of HA-1077, a ROCK inhibitor, improves retinal function in a mouse model of huntington disease," PLoS ONE, vol. 8, no. 2, Article ID e56026, 2013.

[23] Z. Zhang, A. K. Ottens, S. F. Larner et al., "Direct Rho-associated kinase inhibiton induces cofilin dephosphorylation and neurite outgrowth in PC-12 cells," Cellular \& Molecular Biology Letters, vol. 11, no. 1, pp. 12-29, 2006.

[24] M. Dong, B. P. Yan, J. K. Liao, Y.-Y. Lam, G. W. K. Yip, and C.-M. Yu, "Rho-kinase inhibition: a novel therapeutic target for the treatment of cardiovascular diseases," Drug Discovery Today, vol. 15, no. 15-16, pp. 622-629, 2010.

[25] Y. Fujita and T. Yamashita, "Axon growth inhibition by RhoA/ ROCK in the central nervous system," Frontiers in Neuroscience, vol. 8, article 338, 2014.

[26] H. Xiao, C. Neuveut, H. L. Tiffany et al., "Selective CXCR4 antagonism by Tat: implications for in vivo expansion of coreceptor use by HIV-1," Proceedings of the National Academy of Sciences of the United States of America, vol. 97, no. 21, pp. 11466-11471, 2000.

[27] I. E. András, H. Pu, M. A. Deli, A. Nath, B. Hennig, and M. Toborek, "HIV-1 Tat protein alters tight junction protein expression and distribution in cultured brain endothelial cells," Journal of Neuroscience Research, vol. 74, no. 2, pp. 255-265, 2003.

[28] W. Huang, L. Chen, B. Zhang, M. Park, and M. Toborek, "PPAR agonist-mediated protection against HIV Tat-induced cerebrovascular toxicity is enhanced in MMP-9-deficient mice," Journal of Cerebral Blood Flow \& Metabolism, vol. 34, no. 4, pp. 646-653, 2014.

[29] N. Gandhi, Z. M. Saiyed, J. Napuri et al., "Interactive role of human immunodeficiency virus type 1 (HIV-1) clade-specific Tat protein and cocaine in blood-brain barrier dysfunction: implications for HIV-1-associated neurocognitive disorder," Journal of Neurovirology, vol. 16, no. 4, pp. 294-305, 2010.

[30] C. L. Gibson, K. Srivastava, N. Sprigg, P. M. W. Bath, and U. Bayraktutan, "Inhibition of Rho-kinase protects cerebral barrier from ischaemia-evoked injury through modulations of endothelial cell oxidative stress and tight junctions," Journal of Neurochemistry, vol. 129, no. 5, pp. 816-826, 2014.

[31] M. J. Dörfel and O. Huber, "Modulation of tight junction structure and function by kinases and phosphatases targeting occludin," Journal of Biomedicine and Biotechnology, vol. 2012, Article ID 807356, 14 pages, 2012.

[32] Y. Zhong, B. Zhang, S. Y. Eum, and M. Toborek, "HIV-1 Tat triggers nuclear localization of ZO-1 via Rho signaling and
cAMP response element-binding protein activation," Journal of Neuroscience, vol. 32, no. 1, pp. 143-150, 2012.

[33] M. Fujii, K. Duris, O. Altay, Y. Soejima, P. Sherchan, and J. H. Zhang, "Inhibition of Rho kinase by hydroxyfasudil attenuates brain edema after subarachnoid hemorrhage in rats," Neurochemistry International, vol. 60, no. 3, pp. 327-333, 2012.

[34] R. Xu, X. Feng, X. Xie, J. Zhang, D. Wu, and L. Xu, "HIV-1 Tat protein increases the permeability of brain endothelial cells by both inhibiting occludin expression and cleaving occludin via matrix metalloproteinase-9," Brain Research, vol. 1436, pp. 1319, 2012.

[35] B. V. Zlokovic, R. Deane, A. P. Sagare, R. D. Bell, and E. A. Winkler, "Low-density lipoprotein receptor-related protein1: a serial clearance homeostatic mechanism controlling Alzheimer's amyloid $\beta$-peptide elimination from the brain," Journal of Neurochemistry, vol. 115, no. 5, pp. 1077-1089, 2010.

[36] B. Giunta, Y. Zhou, H. Hou et al., "HIV-1 TAT inhibits microglial phagocytosis of Abeta peptide," International Journal of Clinical and Experimental Pathology, vol. 1, no. 3, pp. 260-275, 2008.

[37] B. Giunta, H. Hou, Y. Zhu et al., "HIV-1 Tat contributes to Alzheimer's disease-like pathology in PSAPP mice," International Journal of Clinical and Experimental Pathology, vol. 2, no. 5, pp. 433-443, 2009.

[38] M. P. Mattson, "Oxidative stress, perturbed calcium homeostasis, and immune dysfunction in Alzheimer's disease," Journal of NeuroVirology, vol. 8, no. 6, pp. 539-550, 2002.

[39] M. Bae, N. Patel, H. Xu et al., "Activation of TRPML1 clears intraneuronal $\mathrm{A} \beta$ in preclinical models of HIV infection," The Journal of Neuroscience, vol. 34, no. 34, pp. 11485-11503, 2014.

[40] B. V. Zloković, M. B. Segal, D. J. Begley, H. Davson, and L. Rakić, "Permeability of the blood-cerebrospinal fluid and blood-brain barriers to thyrotropin-releasing hormone," Brain Research, vol. 358, no. 1-2, pp. 191-199, 1985.

[41] B. V. Zlokovic, M. N. Lipovac, D. J. Begley, H. Davson, and L. Rakić, "Transport of leucine-enkephalin across the bloodbrain barrier in the perfused guinea pig brain," Journal of Neurochemistry, vol. 49, no. 1, pp. 310-315, 1987.

[42] R. Deane, Z. Wu, and B. V. Zlokovic, "RAGE (Yin) versus LRP (Yang) balance regulates Alzheimer amyloid $\beta$-peptide clearance through transport across the blood-brain barrier," Stroke, vol. 35, no. 11, supplement 1, pp. 2628-2631, 2004.

[43] J. E. Donahue, S. L. Flaherty, C. E. Johanson et al., "RAGE, LRP-1, and amyloid-beta protein in Alzheimer's disease," Acta Neuropathologica, vol. 112, no. 4, pp. 405-415, 2006.

[44] J. Herz and P. Marschang, "Coaxing the LDL receptor family into the fold," Cell, vol. 112, no. 3, pp. 289-292, 2003. 


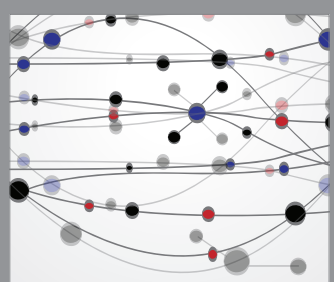

The Scientific World Journal
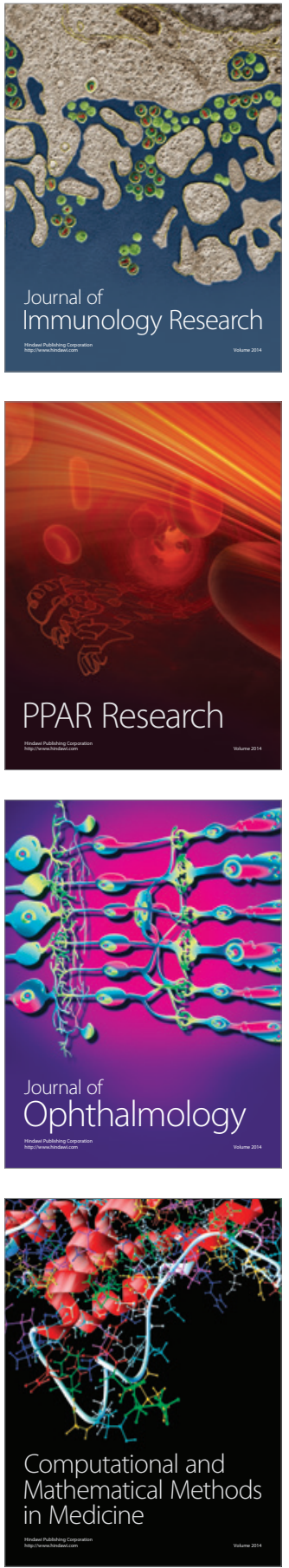

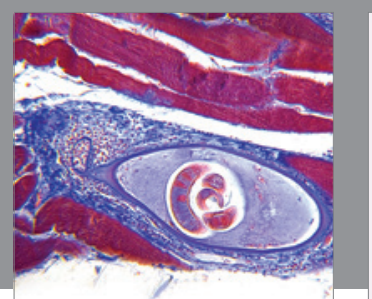

Gastroenterology Research and Practice

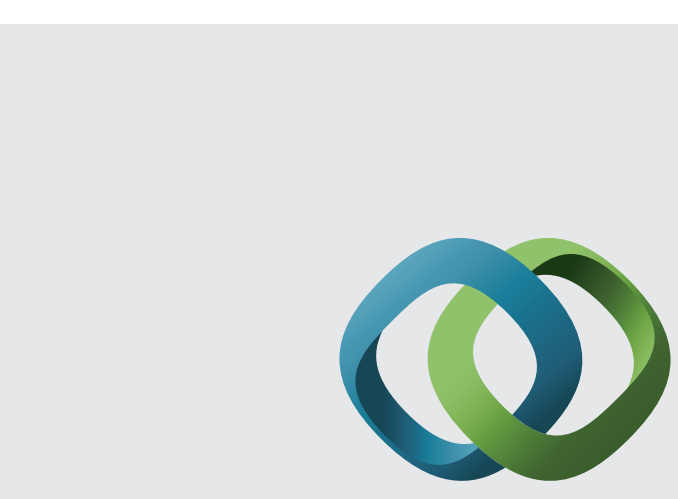

\section{Hindawi}

Submit your manuscripts at

http://www.hindawi.com
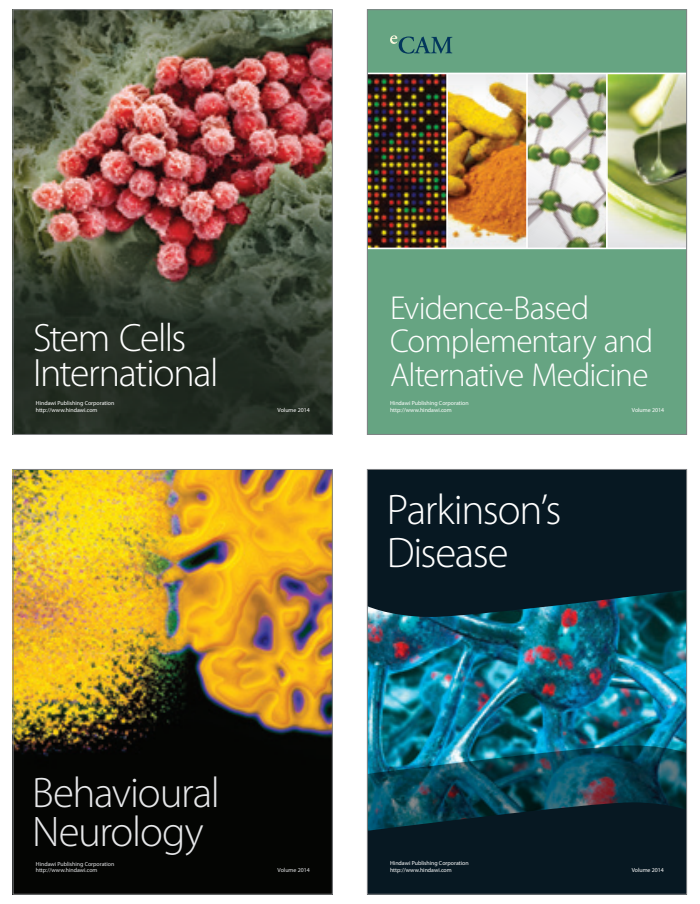
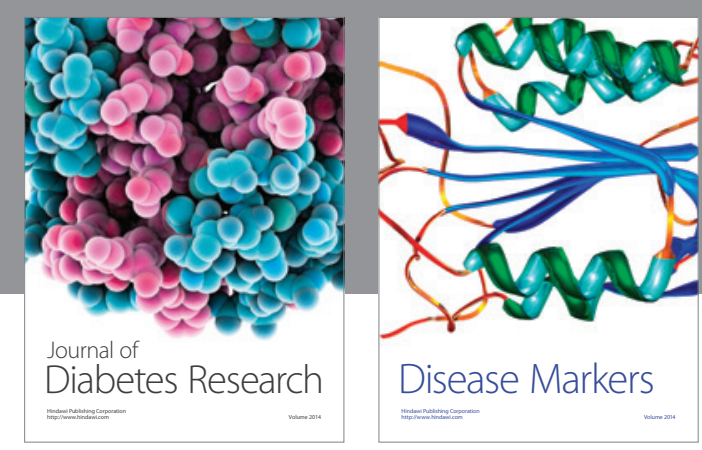

Disease Markers
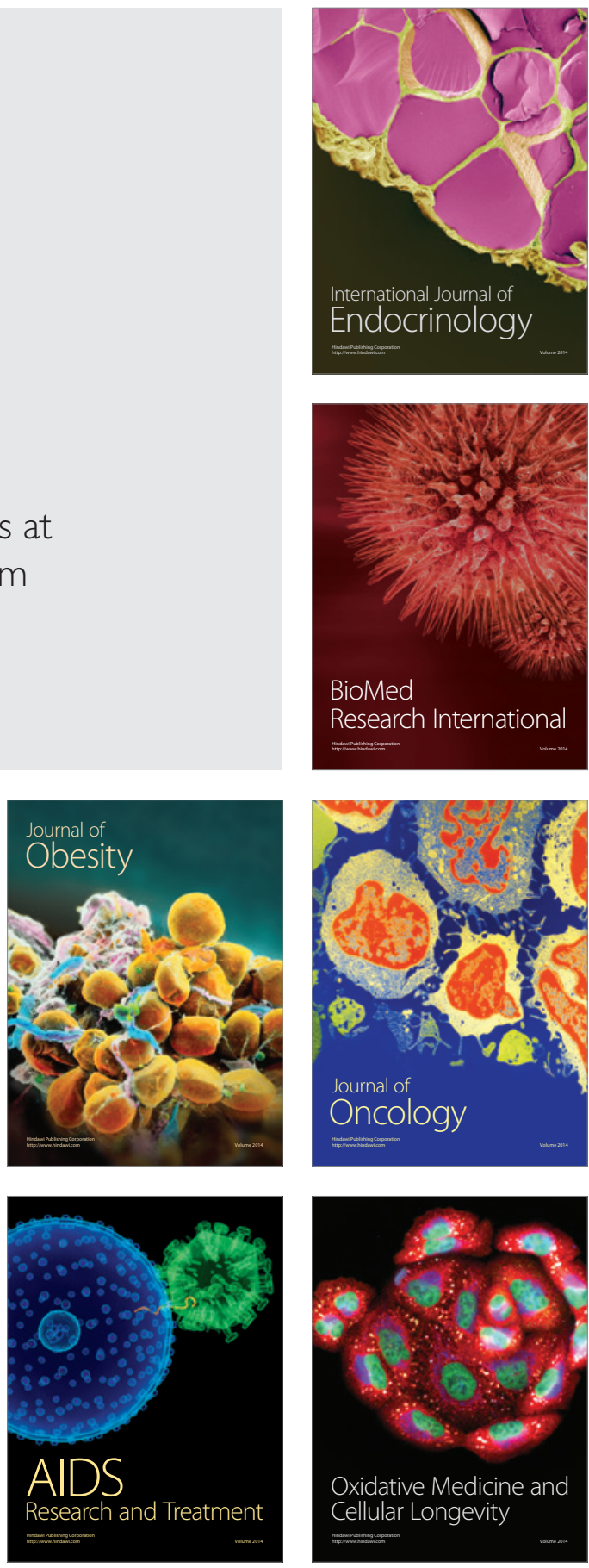